\title{
HUBUNGAN LAMA PEMAKAIAN KONTRASEPSI DENGAN GANGGUAN MENSTRUASI PADA AKSEPTOR KB SUNTIK DI BPM BIDAN E PAMULANG
}

\author{
${ }^{1}$ Holidah, ${ }^{2}$ Citra Paramudita \\ 1,2 Program Studi Diploma III Kebidanan STIKes Widya Dharma Husada \\ ${ }^{1}$ Email: idaholidah74@gmail.com
}

\begin{abstract}
ABSTRAK
Latar Belakang Indonesia sebagai salah satu negara berkembang di dunia terus mengalami peningkatan laju penduduk setiap tahunnya. Hasil estimasi jumlah penduduk pada tahun 2015 tercatat sebanyak 255.461.686 jiwa dari 237.641.326 pada tahun 2010. Menurut Word Health Organization (WHO) angka pengguna kontrasepsi hormonal meningkat signifikan. Cakupan pasangan usia subur hampir 380 juta pasangan menjalankan KB dan 6575 juta diantaranya terutama di negara berkembang menggunakan kontrasepsi hormonal, dengan pengguna terbanyak adalah kontrasepsi suntik yaitu sebesar 38,5\%. Tujuan Penelitian mengetahui adakah hubungan lama pemakaian kontrasepsi dengan gangguan menstruasi pada akseptor KB suntik 3 bulan di BPM Bidan E Pamulang periode Oktober 2018 - Maret 2019. Metode Penelitian menggunakan penelitian deskriptif dengan pendekatan Cross sectional, dimana populasi dalam penelitian ini adalah seluruh akseptor KB suntik 3 bulan di BPM Bidan E Pamulang yang berjumlah 428 responden dan sampel sejumlah 81 responden. Hasil Penelitian terdapat sebagian kecil yaitu $21.0 \%$ responden memakai kontrasepsi dalam jangka singkat dan hampir setengahnya yaitu $40.7 \%$ responden memakai kontrasepsi dalam jangka lama, sebagian besar yaitu $80.2 \%$ responden mengalami gangguan menstruasi serta terdapat hubungan antara lama pemakaian kontrasepsi dengan gangguan menstruasi pada akseptor KB suntik 3 bulan, dimana pada uji statistik Chi-square didapatkan p value $=0.010<0.05$ dan nilai OR yaitu 6.382 (95\% CI 1.342 - 30.357). Saran akseptor KB diharapkan mencari tahu tentang berbagai hal mengenai kontrasepsi sehingga dapat memilih metode kontrasepsi yang efektif dengan berbagai pertimbangan dan sebaiknya tidak menggunakan kontrasepsi hormonal dalam jangka lama karena semakin lama pemakaian kontrasepsi hormonal akan semakin besar resiko untuk mengalami gangguan menstruasi.
\end{abstract}

Kata Kunci: $\quad$ Kontrasepsi Hormonal, KB Suntik 3 Bulan, Gangguan Menstruasi

\begin{abstract}
Background Indonesia as one of the developing countries in the world continues to experience an increase in population rates every year. The results of the estimated population in 2015 were 255,461,686 people from 237,641,326 in 2010. According to the Word Health Organization (WHO) the number of users of hormonal contraception increased significantly. The coverage of couples of childbearing age of nearly 380 million couples runs family planning and 65-75 million of whom are mainly in developing countries using hormonal contraception, with the most users being injection contraception which is $38.5 \%$. Objective was to find out whether there was a long relationship between contraceptive use and menstrual disorders in three months injection family planning acceptors at the Clinic Midwife E Pamulang period October 2018 - March 2019. Methods used descriptive research with cross sectional approach, where the population in this study was all three months injection family planning acceptor at clinic midwife E Pamulang which amounted to 428 respondents while the sample was 81 respondents. Results were a small number of $21.0 \%$ of respondents using contraception in the short term and almost half of them were $40.7 \%$ of respondents using long-term contraception, most of which $80.2 \%$ of respondents experienced menstrual disorders and there was a relationship between the duration of contraception and menstrual disorders in injection family planning acceptors three months, where in the Chi-square statistical test $p$ value $=0.010<0.05$ and OR value is 6.382 (95\% CI 1,342 - 30,357). Suggestions acceptors are expected to find out about varios things about contraception so that they can choose effective cotraception with various consideration and should not use hormonal contraception for a long time because the longer the use of hormonal contraception will be the greater the risk for menstrual disorder
\end{abstract}

Keywords: $\quad$ Hormonal Contraception, Three Months Injection Family Planning, Menstrual Disorders 


\section{LATAR BELAKANG}

Indonesia sebagai salah satu Menurut Word Health negara berkembang di dunia yang terus mengalami peningkatan laju penduduk setiap tahunnya. Hasil estimasi jumlah penduduk pada tahun 2015 tercatat sebanyak 255.461.686 jiwa dari 237.641.326 pada tahun 2010. Oleh karena itu pemerintah mencanangkan program keluarga berencana, guna menekan laju pertumbuhan penduduk serta mewujudkan Norma Keluarga Kecil yang Bahagia dan Sejahtera (NKKBS). (Profil Kementrian Kesehatan Republik Indonesia, 2015).

Program

pencapaian

kesejahteraan bangsa menjadi target Millenium Development Goals sampai tahun 2015. Program Keluarga Berencana Nasional telah memiliki visi dan misi terbaru yaitu dengan visi penduduk tumbuh seimbang tahun 2015 dan misinya mewujudkan pembangunan yang berwawasan kependudukan serta mewujudkan keluarga kecil bahagia sejahtera, yang dimaknai sebagai keluarga yang sehat, maju, dan mandiri dengan ketahanan keluarga yang tinggi (Mardiya, 2009; Muryanta, 2010 dalam Antika, 2014).
Organization (WHO) angka pengguna kontrasepsi hormonal meningkat signifikan. Cakupan pasangan usia subur hampir 380 juta pasangan menjalankan KB dan 65-75 juta diantaranya terutama di negara berkembang menggunakan kontrasepsi hormonal seperti pil, suntik dan implant, dengan pemakaian kontrasepsi hormonal terbanyak adalah kontrasepsi suntik yaitu sebesar 38,5\% (WHO, 2010).

Menurut Kementerian Kesehatan RI tahun 2015 jumlah peserta KB ada sebanyak 42.209.871 dari 47.665.847 PUS. Pengguna kontrasepsi suntik sebanyak 20.307.264 (48,11\%), pil sebanyak $10.138 .682(24,02 \%)$, implan sebanyak $4.406 .117(10,44 \%)$, IUD (Intra Uterine device) sebanyak 4.276.727 (10,13\%), kondom sebanyak $1.482 .065(3,51 \%)$, MOW sebanyak 1.354.294 (3,21\%), dan MOP sebanyak 244.722 (0,58\%) (Sutarjo dan Johan, 2016).

Menurut Badan Pemberdayaan Masyarakat Pemberdayaan Perempuan dan Keluarga Berencana (BPMPPKB) 
Kota Tangerang Selatan, pengguna kontrasepsi pada tahun 2016 mencapai 88.715 jiwa. Pengguna kontrasepsi suntik sebanyak 39.066 (44,04\%), pil sebanyak $17.275 \quad(19,47 \%), \quad$ IUD sebanyak 12.718 (14,34\%), kondom sebanyak $11.739(13,23 \%)$, implan sebanyak $7.189(8,10 \%)$, MOW sebanyak 695 (0,78\%), dan MOP sebanyak $33(0,04 \%)$ (BPMPPKB, 2016).

"Keluarga Berencana merupakan upaya untuk mengatur kelahiran anak, jarak dan usia ideal melahirkan, mengatur kehamilan, melalui promosi, perlindungan, dan bantuan sesuai dengan hak reproduksi untuk mewujudkan keluarga yang berkualitas" (BKKBN, 2011). Sedangkan kontrasepsi adalah cara menghindari atau mencegah terjadinya kehamilan sebagai akibat pertemuan antara sel telur yang matang dengan sel sperma. Kontrasepsi terdiri dari kontrasepsi hormonal (pil, suntik kombinasi, suntik progesteron, implant) dan non hormonal (kondom, IUD, MAL (Metode Amenore Laktasi), dan sistem kalender) (Handayani, 2010). Metode kontrasepsi suntik progestin memiliki efek samping gangguan haid seperti oligomenorea dan polimenorea, spotting, hipermenorea atau hipomenorea, amenorea, sakit kepala, penururnan libido, dan jerawat (Affandi et al., 2012).

Berdasarkan hasil penelitian yang dilakukan oleh Laode Muhammad Sety (2014), menunjukkan bahwa ada hubungan antara pemakaian kontrasepsi pil dengan gangguan menstruasi dengan nilai $p 0.000<0.05$. Ada hubungan antara pemakaian kontrasepsi suntik dengan gangguan menstruasi dengan nilai $p 0.000<0.05$, dan tidak ada hubungan antara pemakaian kontrasepsi implan dengan gangguan menstruasi dengan nilai $p=$ $0.581>0.05$ (Sety, 2014).

Menurut penelitian Munayarokh (2014), Hubungan Lama Pemakaian Kontrasepsi Suntik DMPA Dengan Gangguan Menstruasi di BPM Mariyah Nurlaili Rambe Anak Mungkid, Menunjukan bahwa pada lama pemakaian kontrasepsi suntik DMPA $\leq$ 1 tahun proporsi responden yang mengalami gangguan menstruasi spotting lebih besar (50\%) daripada gangguan menstruasi yang lainnya dan pada lama pemakaian kontrasepsi 
suntik DMPA > 1 tahun responden yang mengalami gangguan menstruasi amenorea lebih besar $(92,9 \%)$ daripada gangguan menstruasi yang lainnya.

Berdasarkan data yang diperoleh di BPM Bidan E Pamulang periode Oktober 2018 - Maret 2019 didapatkan akseptor KB sebanyak 1053 orang. Diantaranya, akseptor KB suntik 1 bulan sebanyak 582 orang $(55,27 \%)$, KB suntik 3 bulan sebanyak 428 orang $(40,65 \%), \mathrm{KB}$ pil sebanyak 41 orang $(3,89 \%)$, dan KB IUD sebanyak 2 orang $(0,19 \%)$.

Data hasil studi pendahuluan yang peneliti lakukan di BPM Bidan E Pamulang, didapatkan dari 15 responden 14 diantaranya mengeluh mengalami gangguan menstruasi berupa tidak haid > 3 bulan dengan lama pemakaian > 12 bulan. Sehubungan dengan banyaknya akseptor KB suntik 3 bulan dengan keluhan gangguan menstruasi, maka penulis tertarik untuk melakukan penelitian mengenai "Hubungan Lama Pemakaian Kontrasepsi dengan Gangguan Menstruasi pada Akseptor KB Suntik 3 Bulan di BPM Bidan E Pamulang Periode Oktober 2018 Maret 2019”.

\section{METODE PENELITIAN}

Desain penelitian yang digunakan dalam penelitian ini adalah penelitian deskriptif dengan pendekatan potong lintang/Cross sectional karena untuk mempelajari dinamika korelasi antara faktor-faktor sebab akibat dengan cara pendekatan, observasi atau pengumpulan data sekaligus untuk menganalisis hubungan lama pemakaian kontrasepsi dengan gangguan menstruasi pada akseptor KB suntik 3 bulan di BPM Bidan E Pamulang periode Oktober 2018 - Maret 2019. Populasi dalam penelitian ini adalah seluruh akseptor KB suntik 3 bulan di BPM Bidan E Pamulang periode Oktober 2018 Maret 2019 yaitu sejumlah 428 responden. Sedangkan pengambilan sampel dilakukan secara accidental sampling dan dari hasil perhitungan dengan rumus Slovin didapatkan jumlah sampel yang digunakan yaitu 54 responden. Variabel dalam penelitian ini terdiri dari variabel independen yaitu lama pemakaian kontrasepsi suntik 3 bulan dan variabel dependen yaitu gangguan menstruasi. Analisis yang digunakan dalam penelitian ini adalah analisis univariat dan bivariat 
dimana uji statistik yang dipakai adalah

uji Chi-Square dengan batas

kemaknaan 0,05.

\section{HASIL DAN PEMBAHASAN}

\section{ANALISIS UNIVARIAT}

Tabel 1. Karakteristik Responden KB Suntik 3 Bulan Berdasarkan Usia di BPM Bidan E Pamulang

\begin{tabular}{|c|c|c|}
\hline Usia & Frekuensi & $\begin{array}{c}\text { Persentase } \\
(\%)\end{array}$ \\
\hline$<20$ tahun & 2 & 2.5 \\
\hline $\begin{array}{c}20-35 \\
\text { tahun }\end{array}$ & 44 & 54.3 \\
\hline$>35$ tahun & 35 & 43.2 \\
\hline Total & 81 & 100.0 \\
\hline
\end{tabular}

Berdasarkan tabel 1 di atas menunjukan bahwa interpretasi data dari 81 responden $\mathrm{KB}$ suntik 3 bulan yang diteliti, hampir setengahnya yaitu $43.2 \%$ responden berusia $>35$ tahun dan hampir tidak ada yaitu $2.5 \%$ responden berusia $<20$ tahun.

Tabel 2. Karakteristik Responden KB Suntik 3 Bulan Berdasarkan Pendidikan di BPM Bidan E Pamulang

\begin{tabular}{lcc}
\hline Pendidikan & Frekuensi & $\begin{array}{c}\text { Persentase } \\
(\%)\end{array}$ \\
\hline SD & 9 & 11.1 \\
SMP & 40 & 49.4 \\
SMA/SMK & 24 & 29.6 \\
Perguruan & 8 & 9.9 \\
Tinggi & & \\
\hline \multicolumn{1}{c}{ Total } & 81 & 100.0 \\
\hline
\end{tabular}

Sumber : Data Primer

Berdasarkan tabel 2. di atas menunjukan bahwa interpretasi data dari 81 responden $\mathrm{KB}$ suntik 3 bulan yang diteliti, hampir setengahnya yaitu $49.4 \%$ responden berpendidikan SMP dan sebagian kecil yaitu 9.9\% responden berpendidikan Perguruan Tinggi.

Tabel 3. Karakteristik Responden KB Suntik 3 Bulan Berdasarkan Pekerjaan di BPM Bidan E Pamulang

\begin{tabular}{|c|c|c|}
\hline Pekerjaan & Frekuensi & $\begin{array}{c}\text { Persentase } \\
(\%)\end{array}$ \\
\hline Wirausaha & 10 & 12.3 \\
\hline Karyawan & 22 & 27.2 \\
\hline Swasta & & \\
\hline Buruh & 7 & 8.6 \\
\hline IRT & 39 & 48.1 \\
\hline PNS & 3 & 3.7 \\
\hline Total & 81 & 100.0 \\
\hline
\end{tabular}

Berdasarkan tabel 3. di atas menunjukan bahwa interpretasi data dari 81 responden KB suntik 3 bulan yang diteliti, hampir setengahnya yaitu $48.1 \%$ responden bekerja sebagai IRT dan hampir tidak ada yaitu $3.7 \%$ responden bekerja sebagai PNS. 
Tabel 4. Karakteristik Responden KB Suntik 3 Bulan Berdasarkan Paritas di BPM Bidan E Pamulang

\begin{tabular}{|c|c|c|}
\hline Paritas & Frekuensi & $\begin{array}{c}\text { Persentase } \\
(\%)\end{array}$ \\
\hline Primipara & 29 & 35.8 \\
\hline Multipara & 49 & 60.5 \\
\hline Grandemultipara & 3 & 3.7 \\
\hline Total & 81 & 100.0 \\
\hline
\end{tabular}

Berdasarkan tabel 4. di atas menunjukan bahwa interpretasi data dari 81 responden KB suntik 3 bulan yang diteliti, lebih dari setengahnya yaitu $60.5 \%$ responden memiliki riwayat paritas dalam kategori multipara dan hampir tidak ada yaitu $3.7 \%$ responden memiliki riwayat paritas dalam kategori grandemultipara.

Tabel 5. Karakteristik Responden KB Suntik 3 Bulan Berdasarkan Lama Pemakaian Kontrasepsi di BPM Bidan E Pamulang

\begin{tabular}{lcc}
\hline $\begin{array}{c}\text { Lama } \\
\text { Pemakaian } \\
\text { Kontrasepsi }\end{array}$ & Frekuensi & $\begin{array}{c}\text { Persentase } \\
(\%)\end{array}$ \\
\hline Singkat & 17 & 21.0 \\
Sedang & 31 & 38.3 \\
Lama & 33 & 40.7 \\
\hline \multicolumn{1}{c}{ Total } & 81 & 100.0 \\
\hline
\end{tabular}

Sumber : Data Primer

Berdasarkan tabel 5. di atas menunjukan bahwa interpretasi data dari 81 responden KB suntik 3 bulan yang diteliti, sebagian kecil yaitu $21.0 \%$ responden memakai kontrasepsi dalam waktu singkat yaitu $\leq 6$ bulan dan hampir setengahnya yaitu $40.7 \%$ responden memakai kontrasepsi dalam waktu lama yaitu > 12 bulan.

Tabel 6. Karakteristik Responden KB Suntik 3 Bulan Berdasarkan Gangguan Menstruasi di BPM Bidan E Pamulang

\begin{tabular}{lcc}
\hline $\begin{array}{c}\text { Gangguan } \\
\text { Menstruasi }\end{array}$ & Frekuensi & $\begin{array}{c}\text { Persentase } \\
(\%)\end{array}$ \\
\hline Normal & 16 & 19.8 \\
Amenorea & 48 & 59.2 \\
Spotting & 12 & 14.8 \\
Hipermenorea & 2 & 2.5 \\
Oligomenorea & 3 & 3.7 \\
\hline \multicolumn{1}{c}{ Total } & 81 & 100.0 \\
\hline
\end{tabular}

Sumber : Data Primer

Berdasarkan tabel 6. di atas menunjukan bahwa interpretasi data dari 81 responden KB suntik 3 bulan yang diteliti, sebagian besar yaitu $80.2 \%$ responden mengalami gangguan menstruasi dimana lebih dari setengahnya yaitu $59.2 \%$ mengalami amenorea dan hampir tidak ada yaitu $2.5 \%$ mengalami hipermenorea. 


\section{ANALISIS BIVARIAT}

Tabel 7. Distribusi Frekuensi Gangguan Menstruasi Berdasarkan Lama Pemakaian Kontrasepsi di BPM Bidan E Pamulang

\begin{tabular}{|c|c|c|c|c|c|c|c|c|c|}
\hline \multirow{3}{*}{$\begin{array}{c}\text { Lama } \\
\text { Pemakaian } \\
\text { Kontrasepsi }\end{array}$} & \multicolumn{4}{|c|}{ Gangguan Menstruasi } & & & \multirow{3}{*}{$\begin{array}{c}P \\
\text { (value) }\end{array}$} & \multirow{3}{*}{$O R$} & \multirow{3}{*}{$95 \% \mathrm{CI}$} \\
\hline & \multicolumn{2}{|c|}{ Tidak } & \multicolumn{2}{|c|}{ Ya } & \multicolumn{2}{|c|}{ Total } & & & \\
\hline & $\mathrm{F}$ & $\%$ & $\mathrm{~F}$ & $\%$ & $\mathrm{~F}$ & $\%$ & & & \\
\hline Singkat & 14 & 29.2 & 34 & 70.8 & 48 & 100.0 & & & $1.342-$ \\
\hline Lama & 2 & 6.1 & 31 & 93.9 & 33 & 100.0 & .010 & .382 & 30.357 \\
\hline Total & 16 & 19.8 & 65 & 80.2 & 81 & 100.0 & & & \\
\hline
\end{tabular}

Sumber : Data Primer

Berdasarkan tabel 7. di atas menunjukan bahwa interpretasi data dari 81 responden $\mathrm{KB}$ suntik 3 bulan yang diteliti, sebagian besar yaitu $93.9 \%$ responden mengalami gangguan menstruasi dengan lama pemakaian kontrasepsi dalam jangka panjang yaitu > 12 bulan. Hasil uji dengan menggunakan Chi-square menunjukan nilai hitung sebesar 6.5 sedangkan nilai tabel $\square^{\square}$ untuk df = (i - 1) x (j-1) $=(2-1) \times(2-1)=1$ dengan $\alpha=$ $5 \%$ atau 0.05 adalah 3.84. Jadi nilai

$$
(\alpha, \mathrm{df}) \text { yaitu } 6.5>3.84 \text {. }
$$

Kemudian pada uji statsitik Chisquare didapatkan $p$ value sebesar $0.010<0.05$. Dengan demikian Ho ditolak dan Ha diterima yang artinya ada hubungan lama pemakaian kontrasepsi dengan gangguan menstruasi pada akseptor KB suntik 3 bulan.

Nilai OR dalam penelitian ini sebesar 6.382 yang artinya akseptor KB suntik 3 bulan dengan lama pemakaian kontrasepsi jangka lama yaitu > 12 bulan, 6 kali lebih beresiko untuk mengalami gangguan menstruasi dibandingkan dengan akseptor KB suntik 3 bulan dengan lama pemakaian singkat yaitu $\leq 12$ bulan (95\% CI 1.342 - 30.357).

\section{PEMBAHASAN}

\section{Analisis Univariat}

a. Usia

Hasil penelitian menunjukan bahwa interpretasi data dari 81 responden $\mathrm{KB}$ 
suntik 3 bulan yang diteliti, hampir setengahnya yaitu $43.2 \%$ responden berusia $>35$ tahun dan hampir tidak ada yaitu $2.5 \%$ responden berusia $<20$ tahun. Menurut Yanuar (2010), usia seseorang menentukan metode kontrasepsi yang akan dipilih. Semakin tua usia seseorang akan meningkatkan kemungkinan untuk tidak menginginkan kehamilan lagi, serta memilih metode kontrasepsi yang cocok dan efektif. Sedangkan Menurut Hartanto (2010), usia 20 - 35 tahun merupakan fase menjarangkan kehamilan dan merupakan usia yang terbaik untuk mengandung dan melahirkan.

Dengan demikian peneliti berasumsi bahwa $\mathrm{KB}$ suntik 3 bulan lebih efektif jika digunakan oleh responden yang berusia $20-35$ tahun. Sementara responden dengan usia > 35 tahun akan lebih efektif jika menggunakan metode kontrasepsi jangka panjang, seperti implan.

\section{b. Pendidikan}

Hasil penelitian menunjukan bahwa interpretasi data dari 81 responden $\mathrm{KB}$ suntik 3 bulan yang diteliti, hampir setengahnya yaitu
49.4\% responden berpendidikan SMP dan sebagian kecil yaitu 9.9\% responden berpendidikan Perguruan Tinggi. Tingkat pendidikan merupakan salah satu faktor yang menentukan pemilihan suatu metode kontrasepsi karena tingkat pendidikan yang lebih tinggi mampu menyerap informasi dan lebih mampu mempertimbangkan hal-hal yang menguntungkan atau efek samping bagi kesehatan yang berhubungan dengan pemakaian suatu metode kontrasepsi (Yanuar, 2010).

Dengan demikian peneliti berasumsi bahwa pendidikan tidak hanya mempengaruhi pengetahuan tetapi juga pemilihan alat kontrasepsi dan keputusan untuk ber-KB. Sebagaimana seseorang yang berpendidikan rendah, kemungkinan berpengetahuan rendah pula. Sebaliknya, seseorang yang berpendidikan tinggi, maka akan berpengetahuan luas pula sehingga akan mempertimbangkan pemilihan metode kontrasepsi dalam pengambilan keputusan ber-KB. 


\section{c. Pekerjaan}

Hasil penelitian menunjukan bahwa interpretasi data dari 81 responden $\mathrm{KB}$ suntik 3 bulan yang diteliti, hampir setengahnya yaitu $48.1 \%$ responden bekerja sebagai IRT dan hampir tidak ada yaitu $3.7 \%$ responden bekerja sebagai PNS. Pekerjaan tentu erat kaitannya dengan penghasilan atau perekonomian seseorang. Dimana IRT dapat dikatakan sebagai status pekerjaan yang tidak berpenghasilan. Jika dikaitkan dengan masih banyaknya akseptor KB suntik 3 bulan yang berusia >35 tahun dan berpendidikan SMP, bukan suatu ketidakmungkinan jika mereka hanya sebagai IRT. Di samping itu, metode kontrasepsi suntik 3 bulan merupakan salah satu jenis kontrasepsi yang ekonomis dan dapat dijangkau hampir oleh semua kalangan, baik perekonomian menengah ke atas maupun menengah ke bawah.

\section{d. Paritas}

Hasil penelitian menunjukan bahwa interpretasi data dari 81 responden $\mathrm{KB}$ suntik 3 bulan yang diteliti, lebih dari setengahnya yaitu $60.5 \%$ responden memiliki riwayat paritas dalam kategori multipara dan hampir tidak ada yaitu
$3.7 \%$ responden memiliki riwayat paritas dalam kategori grandemultipara. Hasil penelitian ini sejalan dengan penelitian yang dilakukan oleh Herlinawati (2012) RSUD Dr. Pirngadi Medan bahwa dari 86 responden kontrasepsi suntik, terdapat 63 responden yang memiliki riwayat paritas multipara.

Paritas dan jumlah anak masih hidup, erat kaitannya dengan tingkat kesejahteraan. Pada keluarga dengan tingkat kesejahteraan tinggi umumnya lebih mementingkan kualitas anak daripada kuantitas anak. Sementara itu pada keluarga menengah ke bawah, anak dianggap memiliki nilai ekonomi. Pada umumnya keluarga menengah ke bawah lebih banyak mempunyai anak dibandingkan dengan keluarga dengan tingkat ekonomi menengah ke atas. Hal ini disebabkan karena pada umumnya keluarga menengah ke bawah mempunyai tingkat pendidikan rendah, dengan demikian cenderung berpengetahuan rendah pula terutama dalam pengambilan keputusan ber-KB yang berakibat banyak mempunyai anak. Di samping itu, seseorang yang telah memiliki anak $\leq 4$ cenderung memilih metode kontrasepsi suntik karena masih memungkinkan untuk dihentikan jika ingin memiliki anak 
lagi serta harga kontrasepsi yang lebih terjangkau jika dibandingkan dengan metode kontrasepsi jangka panjang, seperti implan.

\section{e. Lama Pemakaian Kontrasepsi}

Hasil penelitian menunjukan bahwa interpretasi data dari 81 responden $\mathrm{KB}$ suntik 3 bulan yang diteliti, sebagian kecil yaitu $21.0 \%$ akseptor KB suntik 3 bulan memakai kontrasepsi dalam waktu singkat yaitu $\leq 6$ bulan dan hampir setengahnya yaitu $40.7 \%$ akseptor $\mathrm{KB}$ suntik 3 bulan memakai kontrasepsi dalam waktu lama yaitu > 12 bulan. Hasil penelitian tentang lama pemakaian kontrasepsi suntik juga dilakukan oleh Mato (2014) pada penelitiannya tentang "Determinan Perubahan Siklus Menstruasi Pada Pengguna Alat Kontrasepsi Suntik Di Wilayah Kerja Puskesmas Ta raweang Kabupaten Pangkep". Hasil penelitiannya menunjukan dari total 30 orang terdapat 22 orang memakai kontrasepsi dalam jangka waktu lama $(73,3 \%)$ dan terdapat 8 orang lainnya memakai kontrasepsi dalam jangka waktu yang tidak lama.

Hal ini sesuai dengan Jurnal Munayarokh (2013) Penggunaan kontrasepsi suntik lebih dari 1 tahun ini sesuai dengan tujuan kontrasepsi yaitu untuk menjarangkan kehamilan dan salah satu dari keuntungan metode kontrasepsi suntik DMPA adalah pencegahan kehamilan jangka panjang. Dengan metode kontrasepsi suntik DMPA ini wanita dapat mengatur jarak kehamilannya sesuai yang diinginkannya dengan lama pemakaian kontrasepsi suntik DMPA.

\section{f. Gangguan Menstruasi}

Hasil penelitian menunjukan bahwa interpretasi data dari 81 responden $\mathrm{KB}$ suntik 3 bulan yang diteliti, sebagian besar yaitu $80.2 \%$ akseptor KB suntik 3 bulan mengalami gangguan menstruasi. Hasil penelitian ini sejalan dengan penelitian Octasari et al., (2014) yang menunjukkan bahwa setelah penggunaan kontrasepsi ada sebanyak 126 orang (60\%) mengalami pola menstruasi tidak teratur. Ini juga sejalan dengan penelitian yang dilakukan oleh Suryati (2014) tentang "Pengaruh Alat Kontrasepsi Suntikan Terhadap Siklus Menstruasi Pada Pasangan Usia Subur (PUS) Di Bidan Praktek Swasta (BPS) Keramuliati Kecamatan Padang Tiji Kabupaten Pidie" bahwa diperoleh hasil dari 25 responden yang memakai alat kontrasepsi suntik 
mayoritas mengalami siklus haid yang tidak normal yaitu sebanyak 21 responden $(84 \%)$.

Hal ini diperkuat oleh pendapat Hartanto (2013) yang menyatakan bahwa KB suntik sebagai kontrasepsi hormonal dapat merangsang ovarium untuk membuat estrogen dan progesteron. Kedua hormon tersebut yang dapat mencegah terjadinya ovulasi sehingga dapat mempengaruhi pola haid yang normal menjadi amenorea, perdarahan ireguler, perdarahan bercak, perubahan dalam frekuensi, lama dan jumlah darah yang hilang.

\section{Analisis Bivariat}

Hasil penelitian menunjukan bahwa Berdasarkan tabel 4.7 di atas menunjukan bahwa interpretasi data dari 81 responden KB suntik 3 bulan yang diteliti, sebagian besar yaitu $93.9 \%$ akseptor KB suntik 3 bulan mengalami gangguan menstruasi dengan lama pemakaian kontrasepsi jangka lama yaitu > 12 bulan. Berdasarkan hasil analisis bivariat tentang hubungan lama pemakaian kontrasepsi dengan gangguan siklus menstruasi pada akseptor KB suntik 3 bulan didapatkan uji statsitik Chi-square didapatkan $p$ value sebesar $0.010<0.05$. Dengan demikian Ho ditolak dan Ha diterima yang artinya ada hubungan lama pemakaian kontrasepsi dengan gangguan menstruasi pada akseptor KB suntik 3 bulan.

Di samping itu pada uji statistik juga didapatkan nilai OR dalam penelitian ini sebesar 6.382 yang artinya akseptor KB suntik 3 bulan dengan lama pemakaian kontrasepsi jangan lama yaitu > 12 bulan, 6 kali lebih beresiko untuk mengalami gangguan menstruasi dibandingkan dengan akseptor KB suntik 3 bulan dengan lama pemakaian singkat yaitu $\leq 12$ bulan $(95 \%$ CI $1.342-30.357)$. Karena pemakaian KB suntik 3 bulan merupakan intervensi dari luar, maka organ reproduksi diharuskan beradaptasi dengan perubahan-perubahan yang mungkin terjadi akibat efek samping dari kontrasepsi tersebut terutama berkaitan dengan terjadinya gangguan menstruasi.

Hasil penelitian ini sejalan dengan hasil penelitian Momole (2013), bahwa ada hubungan yang bermakna antara lama pemakaian KB suntik DMPA (KB suntik 3 bulan) dengan perubahan keteraturan pola menstruasi di Puskesmas Mawea ( $p$ $=0.025, \alpha<0.05)$. Selain itu, penelitian ini juga sejalan dengan penelitian Kansil et al. (2015) yang menunjukan bahwa ada pengaruh lama pemakaian alat kontrasepsi suntik depo provera terhadap 
efek samping gangguan menstruasi akseptor KB suntik 3 bulan, maka dapat dengan nilai $p=0,011$. diambil kesimpulan, antara lain :

Hasil penelitian ini juga diperkuat 1. Gambaran karakteristik responden KB oleh pendapat Hartanto (2013), bahwa suntik 3 bulan yaitu terdapat hampir mekanisme kerja kontrasepsi suntik yaitu setengahnya yaitu $43.2 \%$ berusia $>35$ dengan cara mencegah ovulasi dimana tahun, hampir setengahnya yaitu $49.4 \%$ kadar FSH dan LH menurun dan tidak responden berpendidikan SMP, hampir terjadi sentakan LH. Di samping itu juga mengakibatkan endometrium menjadi setengahnya yaitu $48.1 \%$ responden dangkal dan atrofis dengan keienjarbekerja sebagai IRT, dan lebih dari setengahnya yaitu $60.5 \%$ responden kelenjar yang tidak aktif. Dengan pemakaian jangka lama, endometrium memiliki riwayat paritas dalam kategori multipara.

dapat menjadi sedemikian sedikitnya, 2. Gambaran responden KB suntik 3 bulan sehingga tidak didapatkan atau hanya berdasarkan lama pemakaian kontrasepsi, didapatkan sedikit sekali jaringan bila terdapat hampir setengahnya yaitu $40.7 \%$ dilakukan biopsi. Tetapi perubahan- responden memakai kontrasepsi dalam perubahan tersebut akan kembali menjadi waktu lama yaitu > 12 bulan.

normal dalam waktu 90 hari setelah 3. Gambaran responden KB suntik 3 bulan suntikan DMPA yang terakhir. berdasarkan gangguan menstruasi, Dengan demikian peneliti terdapat sebagian besar yaitu $80.2 \%$ berasumsi bahwa semakin lama responden mengalami gangguan pemakaian KB suntik 3 bulan, maka akan menstruasi.

semakin signifikan pengaruhnya terhadap 4. Terdapat hubungan antara lama gangguan menstruasi. pemakaian kontrasepsi dengan gangguan

\section{KESIMPULAN}

Berdasarkan analisis data dan didapatkan hasil Chi-square $6.5>3.84$ pembahasan hasil penelitian tentang dengan $p$ value $=0.010<0.05$ dan OR hubungan lama pemakaian kontrasepsi 6.382 (95\% CI 1.342-30.357). dengan gangguan siklus menstruasi pada menstruasi pada akseptor $\mathrm{KB}$ suntik 3 bulan, dimana pada uji statistik 


\section{DAFTAR PUSTAKA}

Arikunto, S. 2010. Prosedur Penelitian Kesehatan. Jakarta: Rinekee Cipta.

Badan Pemberdayaan Masyarakat Pemberdayaan Perempuan dan Keluarga Berencana (BPMPPKB) Kota Tangerang Selatan. 2016. Cakupan Penggunaan Kontrasepsi. Tangerang Selatan: BPMPPKB.

BKKBN. 2011. Kamus Istilah Kependudukan dan Keluarga Berencana.

http://www.bkkbn.go.id/arsip/Docume nts/Perpustakaan/Kamus\%20\%20Istil ah\%20KKB.pdf. (Di akses 15 Mei 2019).

Handayani, Sri. 2010. Buku Ajar Pelayanan Keluarga Berencana. Yogyakarta: Pustaka Rihama.

Hartanto, H. 2013. Keluarga Berencana dan Kontrasepsi. Jakarta: Pustaka Sinar Harapan.

Mardiya. 2009. Mewujudkan Keluarga Sejahtera Dalam Perspektif Islam. tersedia dalam: http://www.kulonprogo.co.id. Pada tanggal 10 Mei 2019.

Munayarokh. 2014. Hubungan Lama Pemakaian Kontrasepsi Suntik DMPA dengan Gangguan Menstruasi di BPM Mariyah Murlaili Rambe Anak Mungkid. Magelang: Jurnal Kebidanan.

Muryanta, A. 2010. Menggapai Target MDGs Dalam Program KB Nasional.

Notoatmodjo, S. 2012. Metodologi Penelitian Kesehatan. Jakarta: Rineka Cipta.

Octasari, F. 2014. Hubungan Jenis dan Lama Penggunaan Alat Kontrasepsi
Hormonal Terhadap Gangguan Menstruasi pada Ibu PUS di Kelurahan Binjai Kecamatan Medan Denai Kota Medan Tahun 2014. Medan: Jurnal Kesehatan.

Profil Kementerian Kesehatan Republik Indonesia. 2015. BAB I Demografi. Kementerian Kesehatan Republik Indonesia.

Sety, L.M. 2014. Hubungan Jenis Pemakaian Kontrasepsi Hormonal dengan Gangguan Menstruasi di Wilayah Kerja Puskesmas Poasia Kota Kendari. Jurnal Kesehatan.

Sutarjo, U.S. \& Johan, P.R. 2016. Profil Kesehatan Indonesia Tahun 2015. Jakarta: Kementerian Kesehatan Republik Indonesia.

World Health Organization. 2010. Infant mortality. WHO. 
Edudharma Journal, Vol 3 No 2, September 2019, page 64-76 